\title{
Recent tendencies in wind storm climatology with implications to storm surge statistics in Estonia
}

\author{
Ü. Suursaar ${ }^{1}$, J. Jaagus ${ }^{2} \&$ T. Kullas ${ }^{1}$ \\ ${ }^{1}$ Estonian Marine Institute, University of Tartu, Estonia \\ ${ }^{2}$ Institute of Geography, University of Tartu, Estonia
}

\begin{abstract}
The aim of this paper is to present an overview of Estonian storm climatology and a statistical study of wind storms and storm surges in the coastal waters of Estonia, Baltic Sea. The results show a general positive trend both in local storminess and storm surge heights over the last century. These tendencies are probably associated with increased westerly circulation and cyclonic activity in the Northern Atlantic. While in Estonian tide gauges, the mean sea level rise $(1.5-2.7 \mathrm{~mm} / \mathrm{yr})$ is roughly equal to or insignificantly higher than the recent global sea level rise estimates $(1.5-1.7 \mathrm{~mm} / \mathrm{yr})$, the trend estimates for annual maximum sea levels vary between 3 and $10 \mathrm{~mm} / \mathrm{yr}$ for different tide gauges and study periods. Maximum value analysis revealed that, in general, the empirical data of both annual maximum wind speeds and sea levels follow the Gumbel distribution. However, in some windward bays of western Estonia two storm surge events (in 1967 and 2005) are inconsistent with the theoretical distributions, which indicate that, in these locations, the most extreme sea level events are hardly predictable by means of return statistics.
\end{abstract}

Keywords: climate change, storm surges, hurricanes, sea level, trends.

\section{Introduction}

Estonia lies in the zone of moderate latitudes $\left(57.5^{\circ}-59.5^{\circ} \mathrm{N}\right.$, Fig. 1), which serves as a prolongation of the so-called North Atlantic storm track (e.g. Soomere [1]). As such, the predominant meteorological conditions in the area are characterized by the frequent passage of cyclones, which accordingly cause considerable sea level fluctuations in the nearly tideless eastern section of the 
Baltic Sea. During the last half-century, significant changes in the regional wind regime are evident. Many authors [2,3] have reported increases in both the winter westerly wind speed component and in the winter North Atlantic Oscillation (NAO) index. Also, cyclonic activity has risen both above the North and Baltic Seas and vitalization of coastal processes have been observed in Estonia by Orviku et al [4]. During severe storms in Estonia, the highest economic losses are concentrated in the coastal zone and the worst damages occur mainly due to storm surges. On 7-9 January 2005, the new highest recorded storm surge (275 $\mathrm{cm}$ ) occurred in Pärnu, Estonia, and rise in storm-related risks in the future is foreseen $[5,6]$.

This paper looks at the long-term changes both in wind storm and extreme sea level events. Our aim is also to investigate how changes in wind speed and direction affect sea level in the study area and to discuss the possibility of estimating maximum expected future surge heights in Estonian coastal waters.

\section{Material and methods}

\subsection{Wind and storminess}

At the present time, the network maintained by the Estonian Meteorological and Hydrological Institute (EMHI) includes 21 meteorological stations.

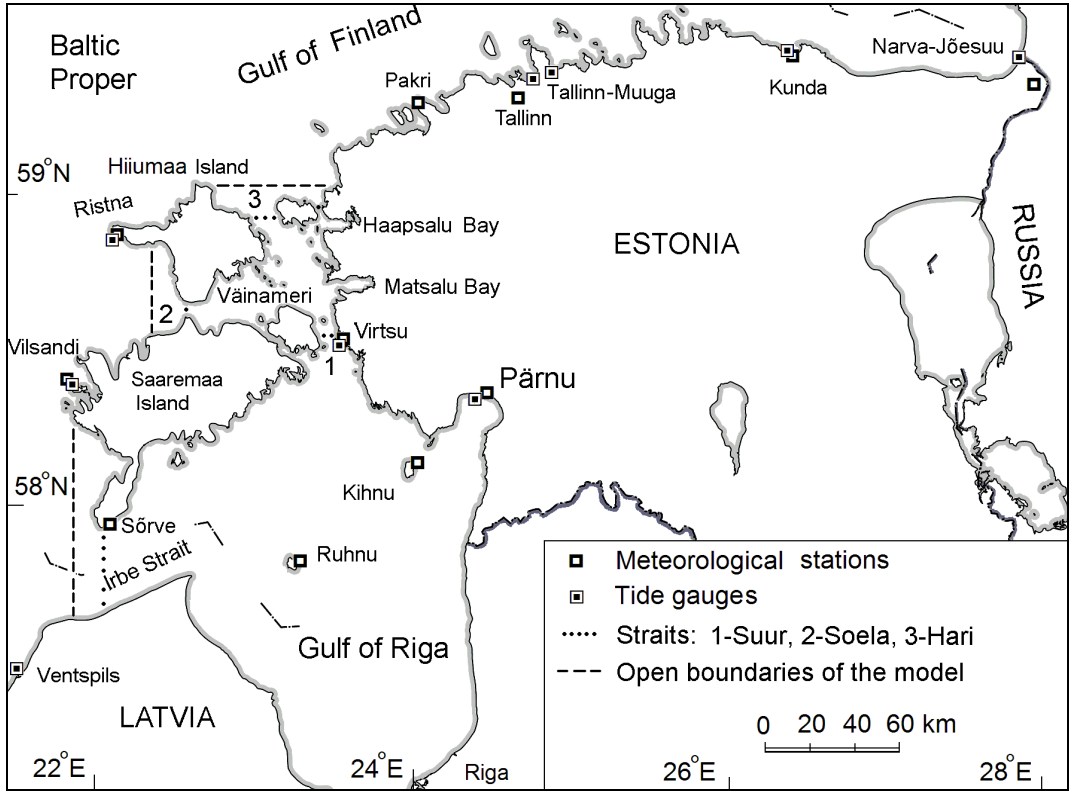

Figure 1: $\quad$ Study area with selected meteorological and tide gauge stations.

Wind data from Kihnu and Vilsandi stations (Fig. 1) were used in this study. The latter has the most open location for wind measurements among all Estonian 
stations and features by the highest long-term mean wind speed $(6.6 \mathrm{~m} / \mathrm{s})$. The stations are equipped with automatic weather stations, which provide data sets of hourly average and gust wind speeds, as well as wind directions.

Historically, time series for wind speeds start in 1855 (at Pakri). Observations started in 1865 at Vilsandi, and in 1931 at Kihnu. However, some changes in methodology and equipment, as well as gaps in data series, considerably abridge the extension of applicable data. Monthly and annual numbers of storm days at Vilsandi station (over the period 1948-2005) and Kihnu (1950-2005) were sorted out for this study. Decadal variations in storm frequency and annual maximum wind speed were studied. A storm was defined when the mean wind speed during a single observation (10 minutes) was $15 \mathrm{~m} / \mathrm{s}$ or higher. A storm day was defined when storms were recorded during at least one observation. The frequency of storms (i.e., the number of storm days per year) was used to measure storminess. The datasets additionally include information about storm intensity, such as the highest mean wind speed, wind direction and duration.

At the stage of pre-treatment, an attempt was made to ensure homogeneity of the data sets of storms. In general, local long-term wind time series can be sensitive for building activity and changes in vegetation near the stations, but also to inhomogeneity caused by instrument changes. An important change from weathercocks to automatic anemorhumbometers took place at Vilsandi and Kihnu on November 1976. The corresponding corrections could be found from professional handbooks. For example, $15 \mathrm{~m} / \mathrm{s}$ mean wind speed corresponds to previous $17 \mathrm{~m} / \mathrm{s}$ and $26 \mathrm{~m} / \mathrm{s}$ equals to previous $30 \mathrm{~m} / \mathrm{s}$. Secondly, the interval of measurements has decreased from 6 hours (prior to 1965) to $3 \mathrm{~h}$, and for the few last years, hourly data is available. In this regard, data about storm duration was used. For example, if there are two consecutive storm wind readings, a storm day can be equally defined both for $6 \mathrm{~h}$ and $3 \mathrm{~h}$ intervals. But the storm day, which is defined by one measurement in case of $3 \mathrm{~h}$ interval, yields just 0.5 storm days on the basis of $6 \mathrm{~h}$ interval.

Extreme value analysis was performed by calculating empirical return periods and fitting theoretical distributions to the samples of annual maximum values.

\subsection{Sea level}

The EMHI operates 12 tide gauges. Automatic tide gauges, which provide hourly data, are currently located at Pärnu, Narva-Jõesuu and Ristna (Fig. 1). We used the databases of monthly mean and extreme sea levels at Pärnu and Tallinn. They represent relative sea level values in regard to the Kronstadt zero benchmark, which is nearly equal to the long-term mean sea level for the Estonian coast. Pärnu has the highest sea level variability among the tide gauges, according to Suursaar et al [5]. In Tallinn, the capital city of Estonia, regular sea level measurements started in 1809. The near continuous data sets are available from 1842, but the measurements were discontinued in 1996 due to construction work at the Port of Tallinn. After that, a mareograph was installed to the nearby Port of Muuga.

Tendencies in sea level time series were analysed using linear regression analysis. Taking into account the gaps, the series for extreme value analysis 
included 83 values at Pärnu (in 1923-2005) and 85 values in Tallinn (in 18991995). In addition to statistical analysis, some sensitivity analyses were carried out using a two-dimensional (2D) hydrodynamic model, which simulates sea level variations depending on wind stress and boundary sea level forcing. The model domain includes both the Gulf of Riga and the Väinameri sub-basins (Fig. 1) with a $1 \mathrm{~km}$ grid resolution, yielding in total 18,964 marine grid-points. For a more detailed model description, see the hindcast studies by Suursaar et al $[5,7]$.

\section{Results and discussion}

\subsection{Tendencies in storminess and their relations to large-scale circulation}

The results show a clear increase by trend both in frequency of storms (Fig. 2ac) and in annual maximum wind speeds (Fig. 2cd). As an average, the number of storm days increased from 16 to 18 at Vilsandi and from 8 to 15 at Kihnu. The increase in maximum wind speed amounted from 19.5 to $22 \mathrm{~m} / \mathrm{s}$ at Vilsandi and from 18 to 22.5 at Kihnu. The trends for Kihnu are statistically significant on $\mathrm{P}<0.05$ level. The presented trends in storm frequency are not as steep as shown in our preliminary analysis for the period of 1950-2002 [4] for two reasons. Firstly, the previous study did not fully take into account the different measuring intervals and the data were a bit understated prior to 1965. Secondly, storminess experiences certain natural cycles with a period of about 35-40 years and the last added years belong to a decreasing phase of this periodicity (Fig. 2). Similar periodicity appears also in the winter NAO index (Fig. 2e), in sea level records both in Estonia (Fig. 3) and in neighbouring countries (e.g. Wakelin et al [8]). According to studies by Jaagus and co-authors (e.g. [4,5]), the rise in storminess appears mainly in winter months, which is connected with the stronger zonal circulation (i.e. westerlies, the NAO) in the same months.

\subsection{Tendencies in sea level}

Time series of annual mean sea levels show slightly increasing tendencies (Fig. 3) with rise rates between 0.1 and $1.0 \mathrm{~mm} / \mathrm{yr}$ in Estonia. With regard to the relative sea level of a location, the two main factors influencing its variations are global sea level change and vertical land movement, which is $+1.5 \mathrm{~mm} / \mathrm{yr}$ at Pärnu and $+1.8 \mathrm{~mm} / \mathrm{yr}$ at Tallinn according to Vallner et al [9]. After adjusting the sea level rates to account for land uplift rates, we calculated sea level rise rates of $1.9 \mathrm{~mm} / \mathrm{yr}$ in Tallinn (1842-1995) and $2.6 \mathrm{~mm} / \mathrm{yr}$ in Pärnu (1924-2005). The estimates for the last 50 years are $1.6 \mathrm{~mm} / \mathrm{yr}$ at Tallinn and $2.7 \mathrm{~mm} / \mathrm{yr}$ at Pärnu (Fig. 3ab). However, the trend estimates for annual maximum sea levels vary between 3 and $10 \mathrm{~mm} / \mathrm{yr}$ for different tide gauges (Fig. 3cd).

Except in Pärnu, the mean sea level rise rates in Estonian tide gauges are roughly equal to or insignificantly higher than the most recent global sea level rise estimates, which are around $1.7 \mathrm{~mm} / \mathrm{yr}$ according to Church and White [10]. 

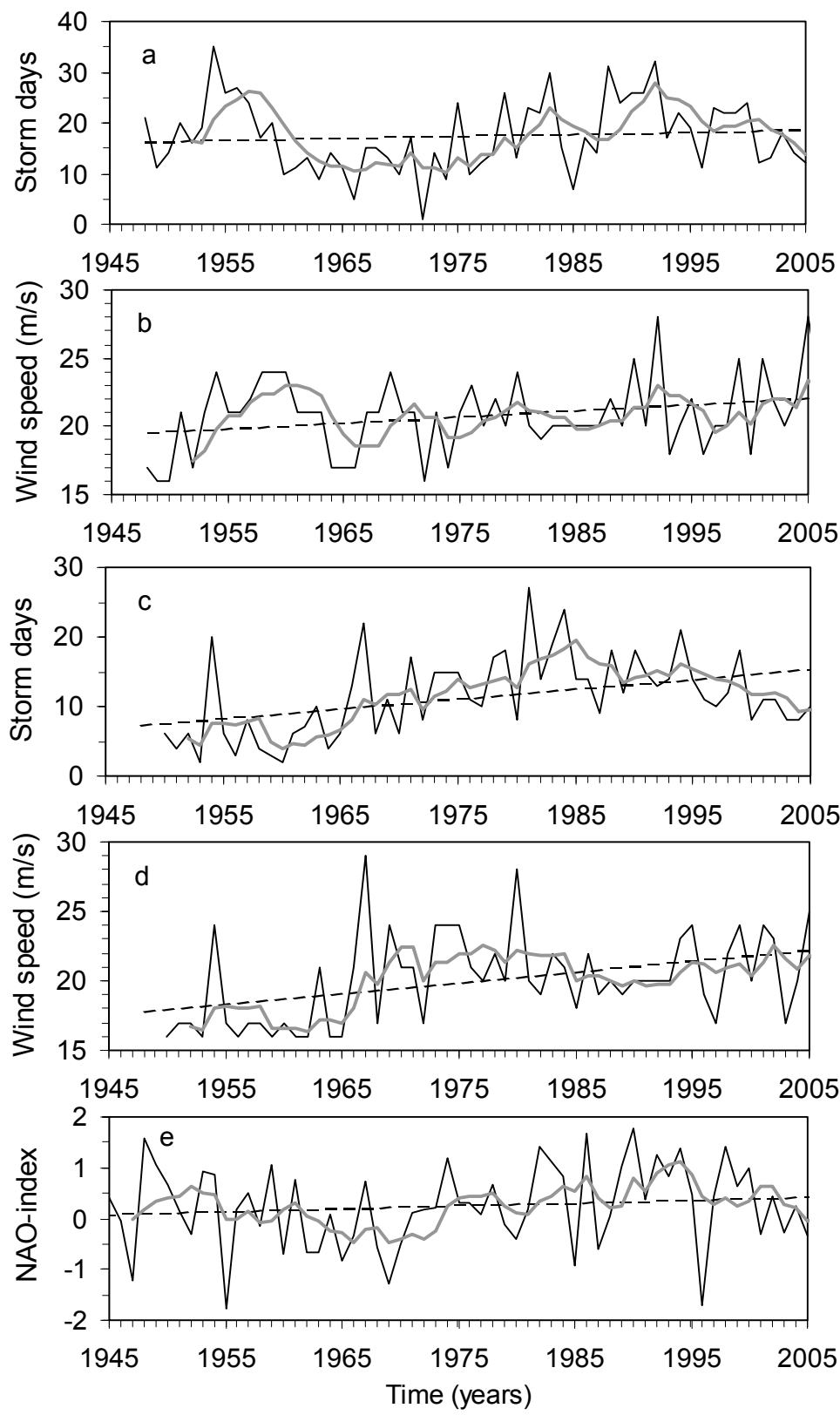

Figure 2: Decadal variations in annual number of storm days at Vilsandi (a) and Kihnu (c), annual maximum wind speeds at Vilsandi (b) and Kihnu (d); variations in the November to March NAO index (e). 9year moving averages and linear trendlines are added to the original series. 

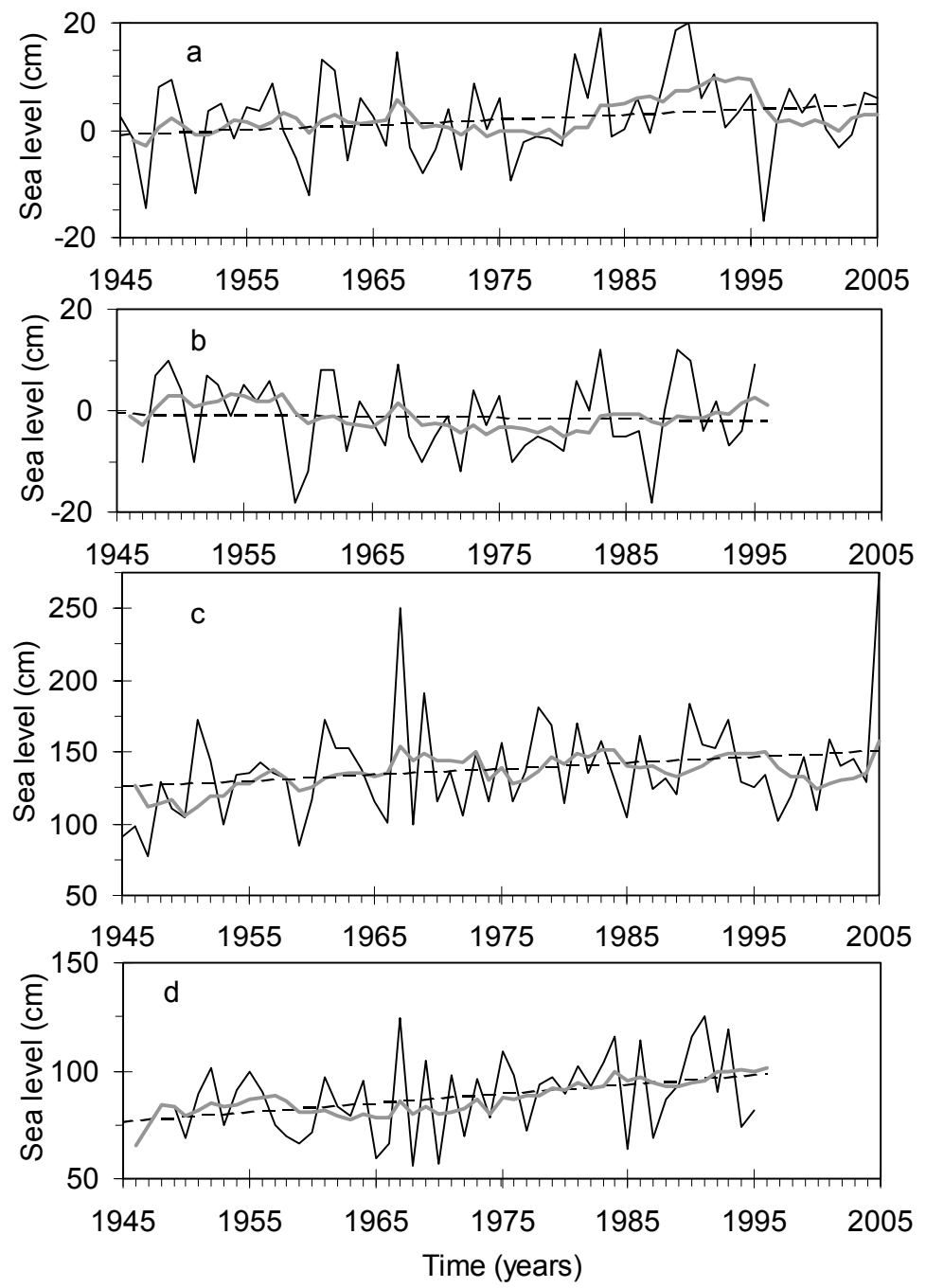

Figure 3: Decadal variations in annual mean relative sea level at Pärnu (a) and Tallinn (c), annual maximum sea levels at Pärnu (b) and Tallinn (d) together with 9-year moving averages and linear trendlines.

Pärnu's positive sea level trends in annual time series appear due to the significantly more positive trends in winter sea level, since during the summer, such trends are less steep or even negative [5]. The significantly higher mean sea level rise in winter correlates with increased local storminess during the same months and with the greater intensity of westerlies in winter, as described also by the NAO index (Figs. 3,2e). The excessive Pärnu sea level rise rate over the global estimates can be explained by hydrodynamic mechanisms, and will be discussed further below. 


\subsection{Tendencies in maximum values and the sensitive coastal areas}

While maximum recorded gust wind speed is $48 \mathrm{~m} / \mathrm{s}$ in Estonia (at Ruhnu in 1969), the maximum corrected sustained wind speeds reach about $30 \mathrm{~m} / \mathrm{s}$ at several stations (Figs. 2,4cd). To find the empirical return periods (Fig. 4), the events were ranked and the observation period was divided by the number of events. Using the least-squares method, mode (a) and scale parameters (b) for theoretical Gumbel distributions were calculated for the stations in question. The corresponding values were 20.1 and 2.1 for Vilsandi, 19.2 and 2.5 for Kihnu, 120.5 and 27.1 for Pärnu, and 76.3 and 14.1 for Tallinn.

The plots against the empirical data show a more or less satisfactory fit in case of maximum wind speeds (Fig. 4cd) and for the sea level (e.g. Fig. 4b) other than sea level at Pärnu (Fig. 4a). Probably no extreme value distribution could predict the two extreme sea level events of $253 \mathrm{~cm}$ in 1967 and of $275 \mathrm{~cm}$ in 2005. Even before $2005,253 \mathrm{~cm}$ was considered as an outlying value with a theoretical recurrence period of some 300-1000 years, but it was repeated and surpassed just 38 years later. The graph (Fig. 4a) is similar to the graphs for gust wind speed that are contaminated by occasional tornados [11], or sea level data that includes tsunami events.
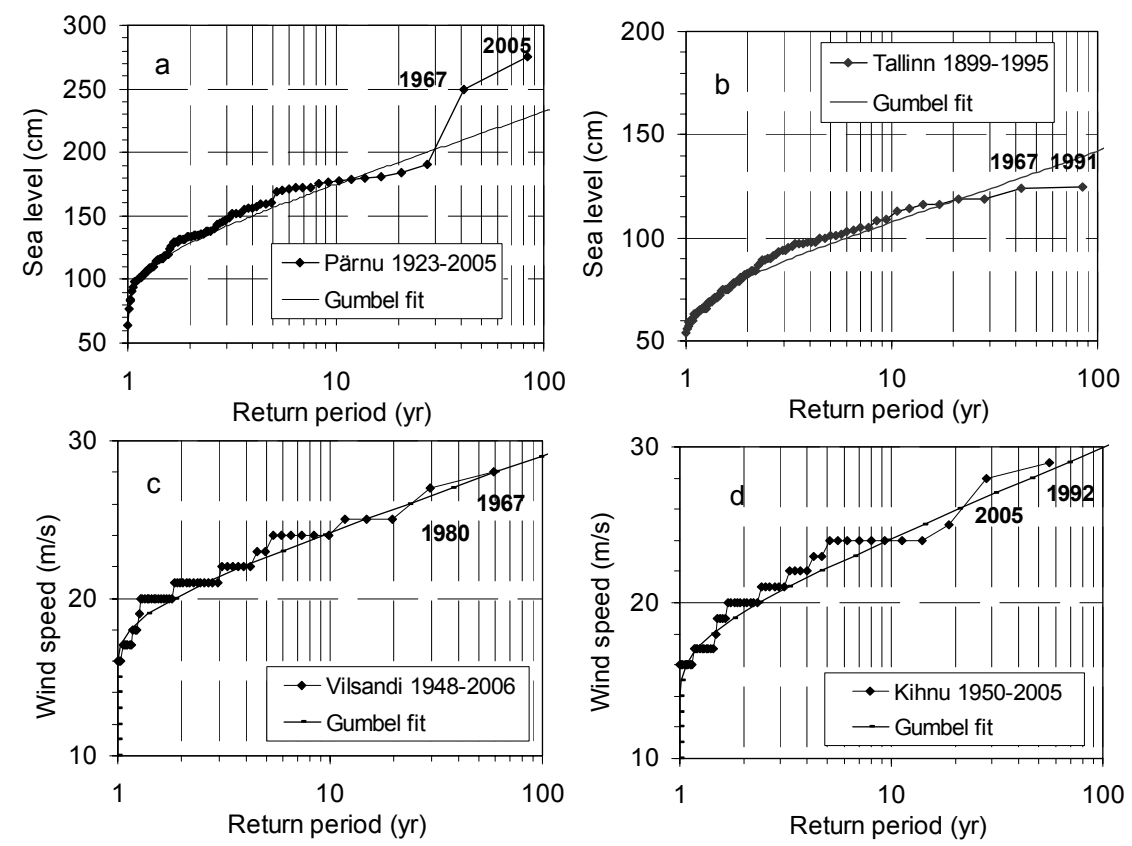

Figure 4: Return periods based on annual maximum sea level data at Pärnu (a) and Tallinn (b), and maximum sustained wind speeds at Vilsandi (c) and Kihnu (d), together with corresponding Gumbel distributions. The years with the highest values are marked for each graph. 
The two anomalous values at Pärnu were nevertheless caused by normal storms. It appeared from a modelling study [5] that due to the specific configuration of the Gulf of Riga and Pärnu Bay, the sea level is proportional to the wind speed in the power of 2.4 at Pärnu Bay. It means that at the upper range of wind speeds, a slight incremental increase yields a progressively higher incremental increase in storm surge level (Fig. 4a). Using a 2D hydrodynamic model, we searched for such highly sensitive locations to wind storm conditions.

To begin, we identified the maximum sea level heights for each grid point of the model domain at a constant wind speed (Fig. 5c). Next, the corresponding wind directions yielding these maximum values were found. The patterns of wind directions resemble tidal charts, particularly in the northern sub-basin of the Väinameri (Fig. 5a), where the phase (wind direction) rotates clockwise around an amphidromic point with zero-amplitude. Fig. 5 demonstrates that the most sensitive areas for wind forcing are the shallow windward bays of Haapsalu, Matsalu and Pärnu. The most effective wind direction for these bays is $220^{\circ}-240^{\circ}$ (SW).

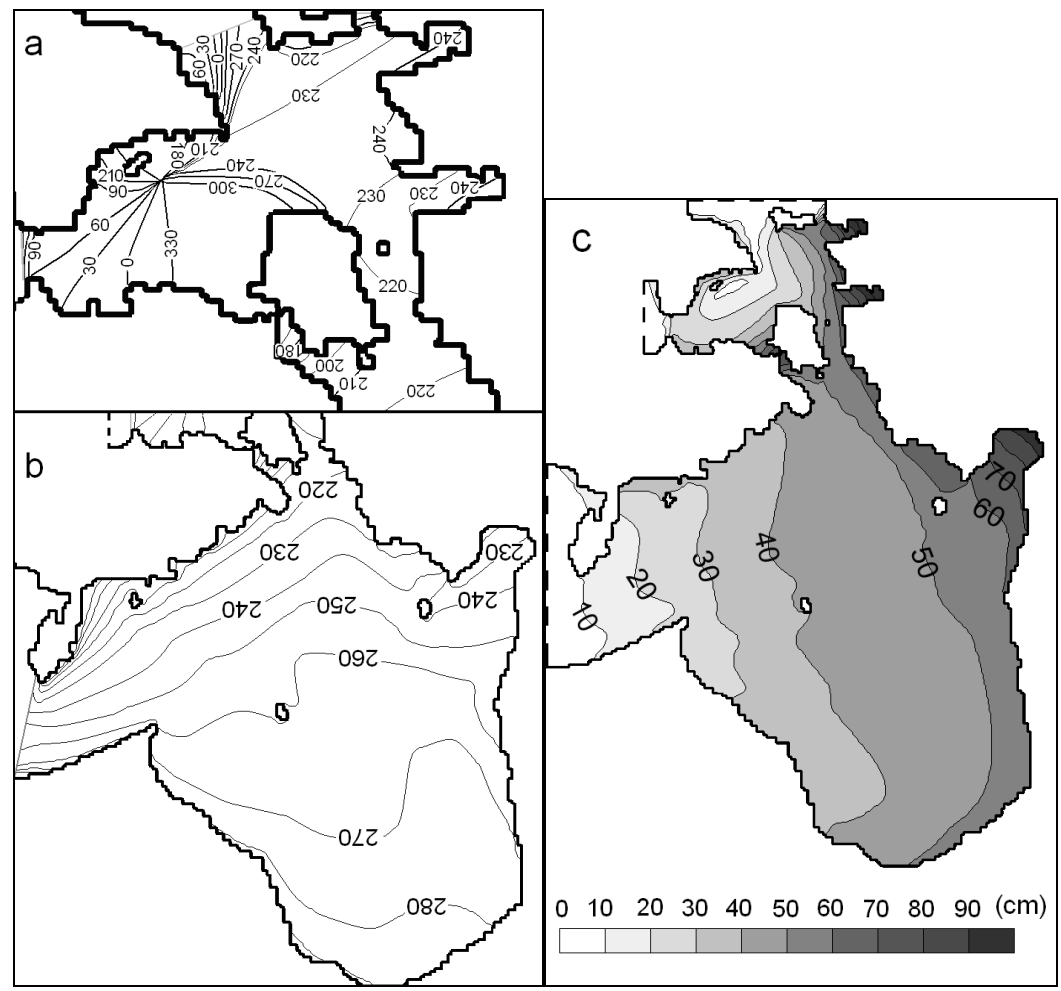

Figure 5: Horizontal distribution of the highest possible sea levels (above the Baltic background sea level) modelled with $20 \mathrm{~m} / \mathrm{s}$ stationary wind (c); the corresponding wind directions that produce the highest sea level of a location at Väinameri (a) and the Gulf of Riga (b). 


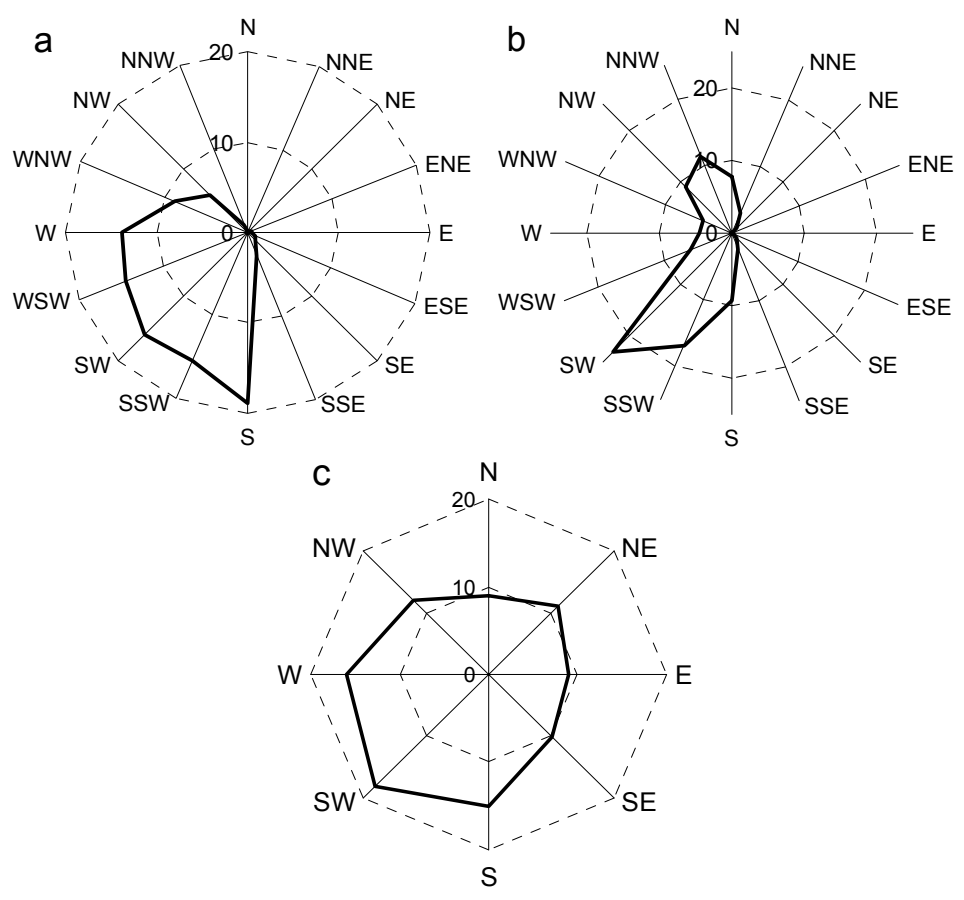

Figure 6: Directional distribution of storm wind events (winds $>15 \mathrm{~m} / \mathrm{s}$ ) at Kihnu (a) and Vilsandi (b) compared to traditional wind rose for all wind directions at Kihnu (c) over the period 1950-2005.

SW is also the most frequent storm wind direction (Fig. 6), as well as the direction where the strongest winds can blow $[1,5]$. Because of the specific configuration and the exposure of bays to the direction of the strongest possible winds (Figs. 5,6), the sea level regime is very sensitive to changes in wind condition. As a result, in case of decadal trend in wind conditions (Fig. 2; [2,3]) the sea level change rates of a semi-enclosed basin can deviate from the global estimates (Fig. 3). A positive trend in wind speed and storminess should result in a steeper than average sea level trend on the windward side and one that is less steep on the leeward side.

\section{Conclusions}

It appeared from the statistical analysis that a positive trend both in local storminess and storm surge heights over the last century is visible in Estonia. These tendencies are associated with increased westerly circulation and cyclonic activity in the Northern Atlantic. At Estonian tide gauges, the mean sea level rise rates (adjusted to take into account the land uplift rates) are $1.5-2.7 \mathrm{~mm} / \mathrm{yr}$ over the last century and the trend estimates for annual maxima vary between 3 and $10 \mathrm{~mm} / \mathrm{yr}$. The trend in the windward-located shallow and narrow Pärnu bay is 
steeper than predicted by the mean global sea level rise estimate and the storm surges in 1967 and 2005 are inconsistent with the theoretical distribution. The excessive rise in local sea level can be explained by the local sea level response to the changing regional wind climate and intensification of cyclones.

The statistical study of storm winds and storm surges can be useful for shipping companies and port authorities, as well as for spatial planners and stakeholders in the coastal regions, which are threatened by wind storms and sea level rise. Using hydrodynamic modelling, such sensitive regions were defined and storm surge mechanisms studied.

\section{Acknowledgements}

The study was supported by the ESF grant projects No. 5763, 5786 and 5929.

\section{References}

[1] Soomere, T., Extreme wind speeds and spatially uniform wind events in the Baltic Proper. Proc. Estonian Acad. Sci. Eng., 7, pp. 195-211, 2001.

[2] Siegismund, F. \& Schrum, C., Decadal changes in the wind forcing over the North Sea. Clim. Res., 18, pp. 39-45, 2001.

[3] Alexandersson, H., Schmidt, T., Iden, K. \& Tuomenvirta, H., Long-term variations of the storm climate over NW Europe. The Global Atmos. Ocean. Syst., 6, pp. 97-120, 1998.

[4] Orviku, K., Jaagus, J., Kont, A., Ratas, U. \& Rivis, R., Increasing activity of coastal processes associated with climate change in Estonia. Journal of Coastal Research, 19, pp. 364-375, 2003.

[5] Suursaar, Ü., Jaagus, J. \& Kullas, T., Past and future changes in sea level near the Estonian coast in relation to changes in wind climate. Boreal Environment Research, 11, pp. 123-142, 2006.

[6] Lowe, J.A., Gregory, J.M. \& Flather, R.A., Changes in the occurrence of storm surges around the United Kingdom under a future climate scenario using dynamic storm surge model driven by the Hadley Centre climate models. Climate Dynamics, 18, pp. 179-188, 2001.

[7] Suursaar, Ü. \& Kullas, T., Influence of wind climate changes on the mean sea level and current regime in the coastal waters of west Estonia, Baltic Sea. Oceanologia, 48, pp. 361-383, 2006.

[8] Wakelin, S.L., Woodworth, P.L., Flather, R.A. \& Williams, J.A., Sealevel dependence on the NAO over the NW European Continental Shelf. Geophys. Res. Lett., 30, Art. No. 1403, 2003.

[9] Vallner, L., Sildvee, H. \& Torim, A., Recent crustal movements in Estonia. J. Geodyn., 9, pp. 215-223, 1988.

[10] Church, J.A. \& White, N.J., A 20th century acceleration in global sealevel rise. Geophys. Res. Lett., 33, L01602, 2006.

[11] Cheng, E. \& Yeung, C., Generalized extreme gust wind speeds distributions. J. Wind Engin. Ind. Aerodyn., 90, pp. 1657-1669, 2002. 